\title{
Dentist's Knowledge of Essential Drug Information Resources in Saudi Arabia
}

Yousef Ahmed Alomi*, (D) BSc. Pharm, MSc. Clin Pharm, BCPS, BCNSP, DiBA, CDE Critical Care Clinical Pharmacists, TPN Clinical Pharmacist, Freelancer Business Planner, Content Editor, and Data Analyst, Riyadh, SAUDI ARABIA.

Anwar Mouslim Alshammari, B.D.S College of Destiney, Hail University, SAUDI ARABIA.

Hanin Sumaydan Saleam Aljohani, Ministry of Health, Riyadh, SAUDI ARABIA.

\section{Correspondence:}

Dr. Yousef Ahmed Alomi, BSc. Pharm, MSc. Clin Pharm, BCPS, BCNSP, DiBA, CDE Critical Care Clinical Pharmacists, TPN

Clinical Pharmacist, Freelancer Business Planner, Content Editor, and Data Analyst, Riyadh, SAUDI ARABIA.

Phone no: +966504417712

E-mail: yalomi@gmail.com
Received: 17-10-2020;

Accepted: 25-12-2020.

Copyright: (c) the author(s),publisher and licensee Pharmacology, Toxicology and Biomedical Reports. This is an open-access article distributed under the terms of the Creative Commons Attribution NonCommercial License, which permits unrestricted non-commercial use, distribution, and reproduction in any medium, provided the original work is properly cited.

This is an open access article distributed under the terms of the Creative Commons AttributionNonCommercial-ShareAlike 4.0 License

Access this article online

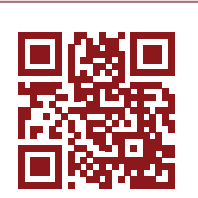

www.ptbreports.org

DOI:

10.5530/PTB.2021.7.4

\begin{abstract}
Objectives: To explore the knowledge of dentists regarding drug information resources in Saudi Arabia. Methods: This is a 4-month cross-sectional study exploring the knowledge of dentists about drug information resources in Saudi Arabia. This is a self-reported electronic survey of dentists. The questionnaire contained two parts. The first section collected demographic data of the responders. In contrast, the second section collected information about dentists' essential knowledge about dental drug information resources, knowledge of the selected 12 dental drug information books, and their preferred 17 websites containing dental drug information resources. We used 5-point Likert response scale system to obtain responses to the close-ended questions. The data were collected through the Survey Monkey system and were analyzed using SPSS and Jeffery's Amazing Statistics Program (JASP). Results: A total of 260 dentists responded to the survey. Of them, $153(59.30 \%)$ were male, and $105(40.7 \%)$ were female, which was statistically significant $(p<0.003)$. The majority of the responders $(257(98.85 \%))$ were in $24-35$ years. Almost half of the responders were interns $(135(51.92 \%))$ followed by residents $(63(24.23 \%))$ and as General Practitioner with (62 $(23.85 \%))$, which was statistically significant $(p<0.001)$. The average score of dentist knowledge about dental drug information resources was 1.80, and the highest score was recorded for knowledge of the concept of dental drug information resources. The average dental knowledge score of dental drug information resources was 1.80 , which was statistically significant $(p<0.5)$. The majority of the responders $(80.70 \%)$ were not familiar with dental drug information books. In contrast, the best resources known by the responders were Martindale: The Complete Drug Reference (55 (21.24\%)) and ADA Dental Drug Handbook (54 (20.77\%)). The majority of the responders (74.30\%) were not familiar with the websites related to dental drug information resources. In comparison, the most frequently used resources by the responders were the World Health Organization (WHO) (137 (52.69\%)) and Ministry of Health websites (137 (52.69\%)). Conclusion: The responders had insufficient knowledge about the available dental drug information resources, including books and websites. Targeting to improve dentist knowledge of dental drug information resources is required in Saudi Arabia through dental schools, and pharmacists play a critical role in dental education.
\end{abstract}

Key words: Dentist, Knowledge, Drug Information, Resources, Saudi Arabia.

\section{INTRODUCTION}

Drug information services are in-depth, unbiased sources of crucial drug information to meet the needs of practicing healthcare professionals, including physicians, pharmacists, and other allied healthcare providers. ${ }^{1}$ Resources of drug information can be classified as primary, secondary, and tertiary sources. In primary resources, all drug information is obtained from journal publications such as reports of clinical drug trials, case reports, and pharmacological research. The most appropriate evidence comes from randomized controlled trials, which requires considerable experience. ${ }^{2-4}$ The secondary sources present as a guide to or review of the primary literature, for example, review paper; meta-analyses; indexes (Index Medicus); abstracts (International Pharmaceutical Abstracts); as well as combinations of abstracts and full-text reprints, for instance, Medline, Current Contents, International Pharmaceutical Abstracts, Index Medicus, Excerpt Medica, and the Iowa Drug Information Service (including full-text reprints of articles). The last class of drug resources is the tertiary or general sources, which Provide documented information in a condensed format. For instance, include formulary manuals, standard treatment manuals, textbooks, available reference books, drug bulletins, and drug compendia. ${ }^{5}$

Regarding kinds of literature, dental school curricula are revised, including significant teaching time devoted to studying drugs and their application. The dentistry practice was slight in pharmacology and toxicology during the past few decades. ${ }^{6}$ With increased pharmacology training at dental schools, a better understanding of dental therapeutics, and the advent of newer drug agents, dentists are now a visible source of prescriptions and drug use. Dental prescriptions are increasing at an approximate rate of 50\% greater than physician prescriptions. This is alarming as there could be potential problems related to drug therapy. The National Center for Health Statistics indicates that there are approximately 295 million visits to dentists per year in the United States and an average of 1.5 visits per person. ${ }^{7}$ Many of which will interact with the therapeutic dental staff. Only the pharmacist is better equipped to supply the needed drug-use information in the Kingdom 
of Saudi Arabia. Although dentists appear to write prescriptions for relatively few drug classes, those drug classes are large and rapidly expanding. Besides, dentists treat patients with many diseases and on many different drugs, all of which may modify the selection of drugs and the application of procedures for dental therapeutics. Therefore, the drug information center must be aware of the current sources of biomedical information in the case of dental literature as recommended by old investigation. ${ }^{8}$ The authors were not aware of study declare the dentist's knowledge of drug information resources locally or gulf and middle Est countries. ${ }^{8}$ This encouraged us to explore the knowledge of dentists with respect to drug information resources in Saudi Arabia.

\section{METHODS}

This is a 4-month cross-sectional study conducted in Saudi Arabia. It is a self-reported electronic survey questionnaire related to dentists. The survey was distributed to dentists from interns to consultants and those belonging to all specialties in dentistry and located in Saudi Arabia. All non-dentists or students and non-completed surveys were excluded from the study. The survey consists of two parts. The first part collected demographic information of the responders. The second part was collected information about responders' essential knowledge of dental drug information resources, their knowledge of selected 12 books on dental drugs, and their knowledge of selected 17 websites on dental medicine. The responses were collected using a 5-point Likert response scale system. In this cross-sectional study, the sample was calculated with an unlimited size of the population, population percentage of $50 \%$, confidence level of $95 \%$ with a $z$ score of 1.96 and margin of error of $5-6.5 \%$, and drop-out rate of $10 \%$. As a result, the sample size was equal to 251 to 432 with a power of study of $80 \% .^{9-11}$ A $60-70 \%$ response rate was required to calculate sample size. ${ }^{11,12}$ The survey was distributed through social media (WhatsApp and Telegram).

A reminder message was sent every two weeks. Expert reviewers and pilot testing validated the survey responses. Moreover, we performed the test of the reliability of the data obtained in this study (Cronbach's alpha). The data were obtained through the Survey Monkey system. Moreover, the Statistical Package of Social Sciences (SPSS), Jeffery's Amazing Statistics Program (JASP), and Microsoft Excel were used for data analysis. Descriptive and frequency analysis, good of fitness analysis, correlation analysis, inferential analysis of factors that affect responder's knowledge about adverse drug reaction and reporting system. The STROBE (strengthening the reporting of observational studies in epidemiology statement: guidelines for reporting observational studies) guided the reporting of this study. ${ }^{13,14}$

\section{RESULTS}

A total of 260 dentists responded to the questionnaire, with maximum responses coming from the northern $(5(28.85 \%))$ followed by the central region $(64(24.62 \%))$ with statistically significant differences between the areas ( $p<0.001)$. Out of 260 responders, $153(59.30 \%)$ were male, and 105 $(40.7 \%)$ were female, which was statistically significant $(p<0.003)$. The majority of the responders $(257(98.85 \%))$ were in the age group of $24-$ 35 years, which was statistically significant for all age groups $(p<0.001)$. Almost half of the responders were interns (135 (51.92\%)) followed by residents $(63(24.23 \%))$ and $62(23.85 \%$ (as General Practitioner with statistically significant differences among them $(p<0.001)$. Most of the responders were the dental staff $(222(85.38 \%))$, with statistically significant differences based on the type of the position held $(p<0.001)$. Most of the responders had three years of experience $(230(88.46 \%))$ followed by non-specialized dentists $(217(84.44 \%))$ with statistically significant differences between the period of experience $(p<0.001)$ (Tables 1 and 2).
The average score of "dentist knowledge of dental drug information resources" was 1.80, with the highest score (2.13) obtained for the element "knowledge of the concept of dental drug information resources." In contrast, the lowest score (1.44) was obtained for "dentist knowledge of the approved list of dental drug information resources at their organization" with statistical significance between the answers at each aspect $(p<0.5)$ (Table 3$)$. Almost $80.70 \%$ of the responders were not familiar with dental drug information books. In contrast, the best resources known by the responders were Martindale: The Complete Drug Reference (55 (21.24\%)) and the ADA Dental Drug Handbook: A Quick Reference (54 (20.77\%)) (Table 4). The majority of the responders (74.30\%) were not familiar with the Internet websites related to dental drug information. The most frequently used resources were the World Health Organization (WHO) (137 (52.69\%)) and Ministry of Health websites (137 (52.69\%)) (Table 5). The reliability test of McDonald's $\omega$ was 0.665 , Cronbach's a was 0.777 , Gultman 2 was 0.794 , and Gultman 6 was 0.823 in regular Biostatistics. In contrast, in Bayesian Biostatistics, the reliability tests were McDonald's $\omega(0.671)$, Cronbach's a (0.775), Gultman 2 (0.794), and Gultman 6 (0.825).

\section{DISCUSSION}

Drug information services refer to a set of services that encompasses specially trained individuals' activities to provide accurate, unbiased, factual drug information, primarily in response to patient-oriented problems. ${ }^{15}$ Nowadays, there has been a rapid expansion in the pharmaceutical market's number and diversity, medication therapy complexity, and the need for evidence-based treatment protocols. This has led to an increased demand for consultation regarding therapeutic indication, medicine selection, comparative effectiveness and safety, proper medication use with current evidence, and updated literature. In this study, we investigated the knowledge of dentists among different drug information resources. With the massive amount of currently available literature, the source of drug information and the quality is

\begin{tabular}{|c|c|c|c|}
\hline Nationality & Response Count & Response Percent & $p$-value \\
\hline Central area & 64 & $24.62 \%$ & \multirow[t]{5}{*}{$<0.001$} \\
\hline North area & 75 & $28.85 \%$ & \\
\hline South area & 31 & $11.92 \%$ & \\
\hline East area & 36 & $13.85 \%$ & \\
\hline West area & 54 & $20.77 \%$ & \\
\hline Answered question & 260 & & \\
\hline Skipped question & 0 & & \\
\hline Gender & Response Count & Response Percent & \\
\hline Male & 153 & $59.30 \%$ & \multirow[t]{2}{*}{$<0.003$} \\
\hline Female & 105 & $40.70 \%$ & \\
\hline Answered question & 258 & & \\
\hline Skipped question & 2 & & \\
\hline Age & Response Count & Response Percent & \\
\hline $24-35$ & 257 & $98.85 \%$ & \multirow[t]{4}{*}{$<0.001$} \\
\hline $36-45$ & 3 & $1.15 \%$ & \\
\hline $46-55$ & 0 & $0.00 \%$ & \\
\hline$>55$ & 0 & $0.00 \%$ & \\
\hline Answered question & 260 & & \\
\hline Skipped question & 0 & & \\
\hline
\end{tabular}




\begin{tabular}{|c|c|c|c|}
\hline Dentist Qualifications & $\begin{array}{l}\text { Response } \\
\text { Count }\end{array}$ & $\begin{array}{c}\text { Response } \\
\text { Percent }\end{array}$ & $\begin{array}{l}\text { p-value } \\
\text { (chi X2) }\end{array}$ \\
\hline Intern & 135 & $51.92 \%$ & \multirow[t]{5}{*}{$<0.001$} \\
\hline Resident & 63 & $24.23 \%$ & \\
\hline General Practitioner & 62 & $23.85 \%$ & \\
\hline Specialist & 0 & $0.00 \%$ & \\
\hline Consultant & 0 & $0.00 \%$ & \\
\hline Answered question & 260 & & \\
\hline Skipped question & 0 & & \\
\hline Position Held & $\begin{array}{l}\text { Response } \\
\text { Count }\end{array}$ & $\begin{array}{c}\text { Response } \\
\text { Percent }\end{array}$ & \\
\hline Director of dental unit & 5 & $1.92 \%$ & \multirow[t]{4}{*}{$<0.001$} \\
\hline $\begin{array}{l}\text { Assistant director of } \\
\text { dental unit }\end{array}$ & 2 & $0.77 \%$ & \\
\hline Dental Director & 31 & $11.92 \%$ & \\
\hline Dental staff & 222 & $85.38 \%$ & \\
\hline Answered question & 260 & & \\
\hline Skipped question & 0 & & \\
\hline $\begin{array}{l}\text { Years of experiences at } \\
\text { Dentists career }\end{array}$ & $\begin{array}{l}\text { Response } \\
\text { Count }\end{array}$ & $\begin{array}{c}\text { Response } \\
\text { Percent }\end{array}$ & \\
\hline$<1$ & 149 & $57.31 \%$ & \multirow[t]{5}{*}{$<0.001$} \\
\hline $1-3$ & 81 & $31.15 \%$ & \\
\hline $4-6$ & 28 & $10.77 \%$ & \\
\hline $7-9$ & 2 & $0.77 \%$ & \\
\hline$>9$ & 0 & $0.00 \%$ & \\
\hline Answered question & 260 & & \\
\hline Skipped question & 0 & & \\
\hline Dentist Specialties & $\begin{array}{c}\text { Response } \\
\text { Count }\end{array}$ & $\begin{array}{c}\text { Response } \\
\text { Percent }\end{array}$ & \\
\hline Dental Public Health & 6 & $2.33 \%$ & \multirow[t]{13}{*}{$<0.001$} \\
\hline Endodontics & 8 & $3.11 \%$ & \\
\hline $\begin{array}{l}\text { Oral and Maxillofacial } \\
\text { Surgery }\end{array}$ & 1 & $0.39 \%$ & \\
\hline $\begin{array}{l}\text { Oral Medicine and } \\
\text { Pathology }\end{array}$ & 0 & $0.00 \%$ & \\
\hline $\begin{array}{l}\text { Oral and Maxillofacial } \\
\text { Radiology }\end{array}$ & 0 & $0.00 \%$ & \\
\hline $\begin{array}{l}\text { Orthodontics and } \\
\text { Dentofacial Orthopedics }\end{array}$ & 1 & $0.39 \%$ & \\
\hline Pediatric Dentistry & 1 & $0.39 \%$ & \\
\hline Periodontics & 0 & $0.00 \%$ & \\
\hline Prosthodontics & 5 & $1.95 \%$ & \\
\hline Restorative dentistry & 18 & $7.00 \%$ & \\
\hline Special needs dentistry & 0 & $0.00 \%$ & \\
\hline Non-applicable & 93 & $36.19 \%$ & \\
\hline General practitioner & 124 & $48.25 \%$ & \\
\hline \multicolumn{4}{|l|}{ Other (please specify) } \\
\hline Answered question & 257 & & \\
\hline Skipped question & 3 & & \\
\hline
\end{tabular}

crucial to utilize the evidence in the clinical setting with paramount confidence. ${ }^{16}$

Each dentistry college has a unique undergraduate and postgraduate curriculum, and each of the specialties has different resources and textbooks as their reference material. Dental medications and their adverse effects are one of the crucial parts of the curriculum. The dental medications have particular reference material to look for and which dentists can refer for studying. Once the students graduate from their school, they require additional resources based on dental care specialties. However, resources on dental medications are needed because daily are used. As a result, we explored dentists' knowledge concerning the selected necessary drug information resources in practice. Our results, most of the responder recently graduated from dental school, either intern or general practitioner. The sample population in this study was good to reflect the practice of the dental population. Our results showed insufficient knowledge of drug information resources in practice, which agrees with the previous research. ${ }^{8}$ The highest score was obtained for the element "learning," which may reflect the internship year's requirements. Most of the responders were not familiar with dental drug information resources, which might be due to various factors; for instance, some dentists might not have studied the drug information resources during their undergraduate course at the school of dentistry or rarely found them in practice. The most frequently read book on dentistry drug information was ADA Dental Drug Handbook: A Quick Reference and Martindale: The Complete Drug Reference, where the quick reference of ADA Dental drug is widespread. At the same time, the Martindale is related to the most common trade name of dental compounding.

The most frequently read online drug resource was ADA Dental Handbook for drug interaction fact or AHF Essential Drug Information. Other drug information resources necessary in dental practice such as BNF or Micromedex Drug Frequency might be duo to finical problem approximately $92.69 \%$ of the responders did not know about Micromedex-Drugdex, the best bio-informative drug reference. Besides, most responders neither knew about Dental Lexi-Drugx nor BNF because dental practitioners do not prescribe drugs regularly. ${ }^{17}$ In this study, we found that the most frequently used website for obtaining drug information was Google Scholar, Ministry of Health $(\mathrm{MOH})$ website, WHO website, or drug.com, which depend on it in their bachelor years that may require research project that a must for their graduation. The websites mentioned above provide general information about dental drugs and do not focus on drug information references. However, most of the responders frequently accessed the drug.com website, which is fast and free of charge. Most of the responders did not often use drug information websites as applications that related to dentists. This study showed that dentists' knowledge of drug information resources was low and not organized in Saudi Arabia. They need education and training to use the best dentistry medications during their undergraduate and postgraduate courses. The curriculum should be regularly updated at their college of dentistry in Saudi Arabia.

\section{Limitations}

This study had various advantages related to dental drug information resources. However, it had few disadvantages: most of the responders were intern or recently graduated, which did not reflect the qualification of the entire population, and the reliability of this study did not reach the optimal level. This necessitates further exploration regarding the type of questions to obtain a good reliability test score.

\section{CONCLUSION}

In this study, we explored dentists' current knowledge about dental information resources in the Kingdom of Saudi Arabia. This study showed that dentists' knowledge regarding dental drug information 


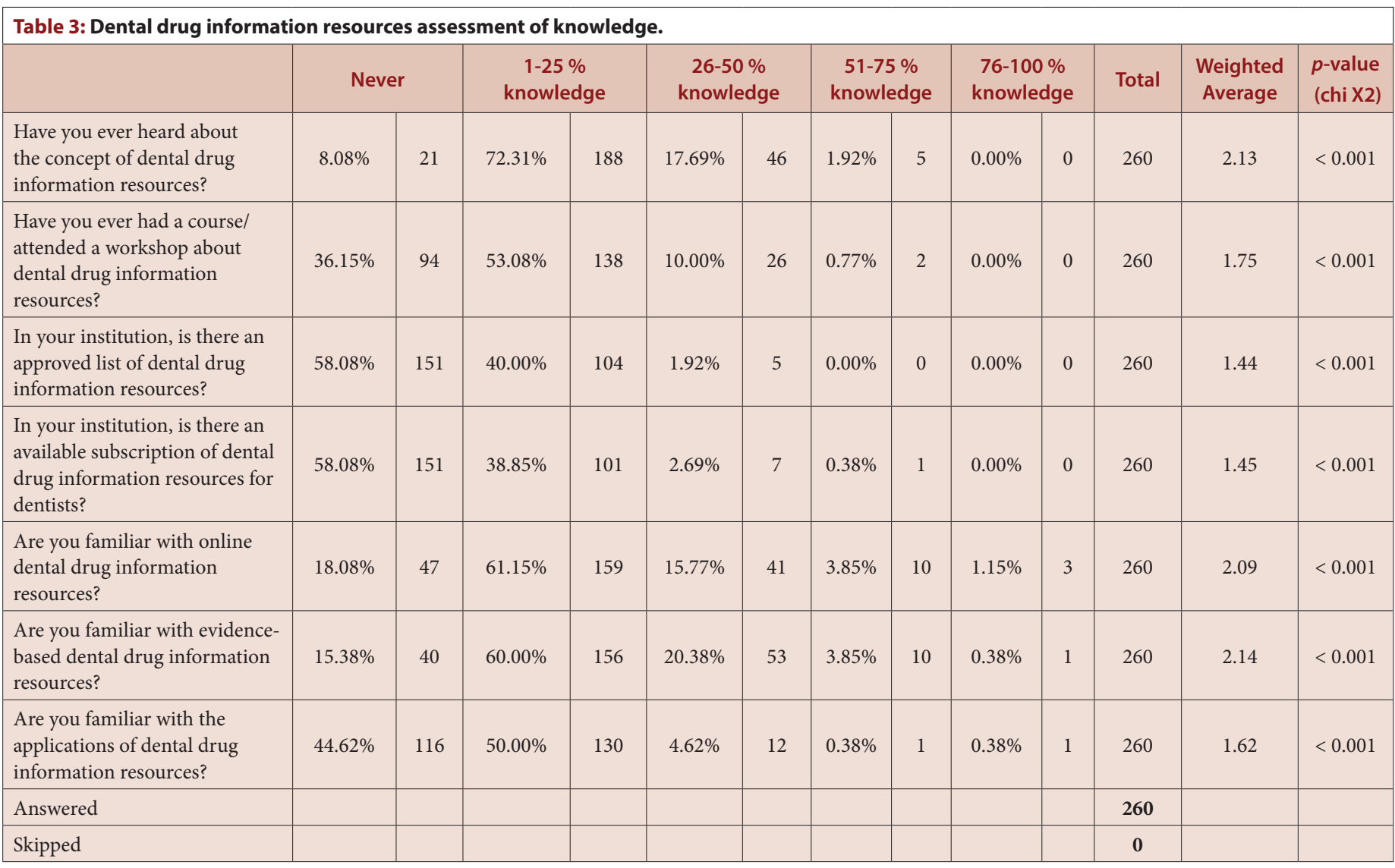

\begin{tabular}{|c|c|c|c|c|c|c|c|c|c|c|c|}
\hline \multirow[b]{2}{*}{ Micromedex-Drugdex } & \multicolumn{2}{|c|}{ Book } & \multicolumn{2}{|c|}{ Online } & \multicolumn{2}{|c|}{ Application } & \multicolumn{2}{|c|}{$\begin{array}{l}\text { I do not know this } \\
\text { reference }\end{array}$} & \multicolumn{2}{|c|}{$\begin{array}{l}\text { Available at your } \\
\text { institution }\end{array}$} & \multirow{2}{*}{$\begin{array}{r}\text { Total } \\
260\end{array}$} \\
\hline & $2.31 \%$ & 6 & $5.38 \%$ & 14 & $0.00 \%$ & 0 & $92.69 \%$ & 241 & $0.00 \%$ & 0 & \\
\hline Dental Lexi-Drugdex & $1.55 \%$ & 4 & $8.91 \%$ & 23 & $0.39 \%$ & 1 & $89.15 \%$ & 230 & $0.39 \%$ & 1 & 258 \\
\hline $\begin{array}{l}\text { AHFS Essential (Adults } \\
\text { and Pediatrics) }\end{array}$ & $2.33 \%$ & 6 & $17.51 \%$ & 45 & $0.78 \%$ & 2 & $81.32 \%$ & 209 & $0.00 \%$ & 0 & 257 \\
\hline $\begin{array}{l}\text { Sanford guide to } \\
\text { antimicrobial therapy }\end{array}$ & $1.54 \%$ & 4 & $8.08 \%$ & 21 & $0.38 \%$ & 1 & $90.38 \%$ & 235 & $0.00 \%$ & 0 & 260 \\
\hline Merck Manual & $17.37 \%$ & 45 & $8.11 \%$ & 21 & $0.00 \%$ & 0 & $76.06 \%$ & 197 & $0.39 \%$ & 1 & 259 \\
\hline $\mathrm{BNF}$ & $1.54 \%$ & 4 & $10.38 \%$ & 27 & $0.00 \%$ & 0 & $89.23 \%$ & 232 & $0.00 \%$ & 0 & 260 \\
\hline $\begin{array}{l}\text { Physician Desk } \\
\text { References (PDR) }\end{array}$ & $1.54 \%$ & 4 & $6.92 \%$ & 18 & $0.38 \%$ & 1 & $91.92 \%$ & 239 & $0.00 \%$ & 0 & 260 \\
\hline BNF pediatric & $2.70 \%$ & 7 & $10.81 \%$ & 28 & $0.00 \%$ & 0 & $87.64 \%$ & 227 & $0.00 \%$ & 0 & 259 \\
\hline Drug Interaction Facts & $5.45 \%$ & 14 & $22.18 \%$ & 57 & $0.78 \%$ & 2 & $72.76 \%$ & 187 & $0.39 \%$ & 1 & 257 \\
\hline $\begin{array}{l}\text { Mosby's Dental Drug } \\
\text { Reference }\end{array}$ & $2.31 \%$ & 6 & $7.31 \%$ & 19 & $0.38 \%$ & 1 & $90.77 \%$ & 236 & $0.00 \%$ & 0 & 260 \\
\hline $\begin{array}{l}\text { Martindale - The } \\
\text { Complete Drug } \\
\text { Reference }\end{array}$ & $21.24 \%$ & 55 & $10.04 \%$ & 26 & $0.00 \%$ & 0 & $69.50 \%$ & 180 & $0.00 \%$ & 0 & 259 \\
\hline $\begin{array}{l}\text { ADA Dental Drug } \\
\text { Handbook: A Quick } \\
\text { Reference }\end{array}$ & $20.77 \%$ & 54 & $58.46 \%$ & 152 & $0.77 \%$ & 2 & $36.92 \%$ & 96 & $0.00 \%$ & 0 & 260 \\
\hline Other (please specify) & & & & & & & & & & & 0 \\
\hline Answered & & & & & & & & & & & 260 \\
\hline Skipped & & & & & & & & & & & 0 \\
\hline
\end{tabular}




\begin{tabular}{|c|c|c|c|c|c|c|c|}
\hline \multirow[b]{2}{*}{ LexisNexis } & \multicolumn{2}{|c|}{ Online } & \multicolumn{2}{|c|}{ Application } & \multicolumn{2}{|c|}{ I do not know this reference. } & \multirow{2}{*}{$\begin{array}{c}\text { Total } \\
259\end{array}$} \\
\hline & $6.95 \%$ & 18 & $0.39 \%$ & 1 & $92.66 \%$ & 240 & \\
\hline National Institutes of Health & $14.34 \%$ & 37 & $0.00 \%$ & 0 & $85.66 \%$ & 221 & 258 \\
\hline Medscape & $2.72 \%$ & 7 & $1.17 \%$ & 3 & $96.50 \%$ & 248 & 257 \\
\hline Microsoft academic. & $3.52 \%$ & 9 & $0.78 \%$ & 2 & $95.70 \%$ & 245 & 256 \\
\hline WebMD & $9.62 \%$ & 25 & $0.00 \%$ & 0 & $90.38 \%$ & 235 & 260 \\
\hline Drug.com & $43.19 \%$ & 111 & $1.17 \%$ & 3 & $56.03 \%$ & 144 & 257 \\
\hline $\begin{array}{l}\text { Center of Diseases Control } \\
\text { (CDC) }\end{array}$ & $41.92 \%$ & 109 & $0.77 \%$ & 2 & $57.69 \%$ & 150 & 260 \\
\hline Daily-med & $30.50 \%$ & 79 & $0.00 \%$ & 0 & $69.50 \%$ & 180 & 259 \\
\hline Medline-plus & $6.92 \%$ & 18 & $0.77 \%$ & 2 & $92.31 \%$ & 240 & 260 \\
\hline Ministry of Health $(\mathrm{MOH})$ & $52.69 \%$ & 137 & $4.23 \%$ & 11 & $44.62 \%$ & 116 & 260 \\
\hline Medpage & $6.18 \%$ & 16 & $0.77 \%$ & 2 & $93.05 \%$ & 241 & 259 \\
\hline Clinical key & $10.85 \%$ & 28 & $0.00 \%$ & 0 & $89.15 \%$ & 230 & 258 \\
\hline Other (please specify) & & & & & & & 0 \\
\hline Answered & & & & & & & 260 \\
\hline Skipped & & & & & & & 0 \\
\hline
\end{tabular}

resources was inadequate, including knowledge about various books and internet resources. Therefore, we recommend increasing steps in educating and training dentists across the Kingdom of Saudi Arabia. Pharmacists play an essential role in the training provided on dental drug information resources.

\section{ACKNOWLEDGEMENT}

None.

\section{CONFLICT OF INTEREST}

The authors declare that there is no conflict of interest.

\section{Funding}

None

\section{Consent for Publications}

Informed consent was obtained from all the participants

\section{Ethical Approval}

This research is exempted from research and ethical committee or an institutional review board (IRB) approval.

https://www.hhs.gov/ohrp/regulations-and-policy/decisioncharts-2018/index.html

\section{ABBREVIATIONS}

MOH: Ministry of Health; KSA: Kingdom of Saudi Arabia; SPSS: Statistical package of social sciences; JASP: Jeffery's Amazing Statistics Program; STROBE: Strengthening the reporting of observational studies in epidemiology.

\section{ORCID ID}

Yousef Ahmed Alomi (iD https://orcid.org/0000-0003-1381-628X

\section{REFERENCES}

1. Pradhan SC. The performance of Drug Information Center at the University of Kansas Medical Center, Kansas City, USA - Experiences, and evaluations. Indian J Pharmacol. 2002;34(2):123-9.

2. Nibu P, Ramesh M, Parthasarathi G. Review of a Drug Information Service in an Indian Teaching Hospital. Aust J Hosp Pharm. 2001;31(2):144-5.

3. Cuddy PG, Elenbaas RM, Elenbaas JK. Evaluating the medical literature part I: Abstract, introduction, methods. Ann Emerg Med. 1983;12(9):549-55.

4. Elenbaas RM, Elenbaas JK, Cuddy PG. Evaluating the medical literature part II: Statistical analysis. Ann Emerg Med. 1983;12(10):610-20.

5. Elenbaas JK, Cuddy PG, Elenbaas RM. Evaluating the medical literature, Part III: Results and discussion. Ann Emerg Med. 1983;12(11):679-86.

6. Koehler HM. Sources of biomedical information in the dental literature. Ther Innov Regul Sci. 1975;9(1):30-1.

7. Hussar DA. Interactions involving drugs used in dental practice. J Am Dent Assoc. 1973;87(2):349-58

8. Parker WA, Reid LW. Dentist attitudes toward drug information resources. Ther Innov Regul Sci. 1978;12(2):84-4.

9. Charan J, Biswas T. How to calculate sample size for different study designs in medical research?. Indian Journal of Psychological Medicine. 2013;35(2):121-6.

10. Pourhoseingholi MA, Vahedi M, Rahimzadeh M. Sample size calculation in medical studies. Gastroenterol Hepatol from Bed to Bench. 2013;6(1):14-7.

11. Ezhumalai G. How big a sample do I need require. Ann SBV. 2017;6(1):39-41.

12. Johnson TP, Wislar JS. Response rates and nonresponse errors in surveys. Vol. 307, JAMA. 2012.307; 1805-6.

13. Elm FV, Douglas G. Altman, Matthias Egger, Stuart J. Pocock, Peter C. Gøtzsche JPV. The Strengthening the Reporting of Observational Studies in Epidemiology (STROBE) Statement: Guidelines for Reporting Observational Studies. PLoS Med. 2007;4(10):1623-7.

14. Elm FV, Altman DG, Egger M, Pocock SJ, Gøtzsche PC, Vandenbroucke JP. The Strengthening the Reporting of Observational Studies in Epidemiology (STROBE) statement: guidelines for reporting observational studies. Lancet 
2007; 370: 1453-57.

15. Rajanandh MG, Varghese R, Ramasamy C. Assessment of drug information services in a south Indian tertiary care hospital in Kanchipuram district. Int J Pharm Pharm Sci. 2011;3(3):273-6.
16. Fernandez-Llimos F. Quality of drug information for healthcare professionals: The ARCA acronym. Pharmacy Practice. 2015;13(4):709.

17. Brinkman DJ, Nijland N, Diermen DEV, Bruers JJM, Ligthart WSM, Rietveld PJ, et al. Are Dutch dental students and dental-care providers competent prescribers of drugs?. Eur J Oral Sci. 2019;127(6):531-8. 